\title{
AMPLIANDO A COMPREENSÃO DO PROCESSO DE VIDA DO IDOSO E DE SUAS NECESSIDADES
}

\author{
AMPLIFYING THE UNDERSTANDING OF ELDERLY'S LIFE \\ PROCCESS AND NEEDS
}

Sarapathy N. T. G. Mendonça ${ }^{1}$

Evanilda Teixeira ${ }^{2}$

MENDONCA, S. N. T. G.; TEIXEIRA, E. Ampliando a compreensão do processo de vida do idoso e de suas necessidades. Rev. Bras. Cresc. De. env. Hum., Sao Paulo, 12 (2), 2002.

Resumo: Este trabalho contempla alguns aspectos psicossociais e fisiológicos do idoso, com a indicação de que esta população deve ser privilegiada como um mercado consumidor específico pois, embora tenha havido um expressivo crescimento populacional desta faixa etária, no Brasil e no mundo, os idosos ainda se encontram discriminados como mercado de consumo. Aponta especificamente para a necessidade de haver uma adequação dos produtos alimentares of erecidos à especificidade alimentar das pessoas idosas, explicitando algumas das características de seu status nutricional e fisiológico ao qual deveria corresponder e dar suporte.

Palavras chave: idoso; fisiologia; status nutricional; osteoporose; envelhecimento.

\section{INTRODUÇÃO}

No Brasil a população idosa está em ascensão, havendo uma projeção de que no ano 2025 sejam 30 milhões. A esperança média de vida tem aumentado três meses por ano, sendo que a população a aposentar-se ou já aposentada cresce mais que a economicamente ativa, fato que levará a modificações econômicas e sociais, reduzindo, em decorrência a renda dos idosos. Segundo estatísticas da Organização Mundial de Saúde, o Brasil será, até o ano de 2050 , o $6^{\circ}$ país do mundo em número de idosos com mais de 60 anos, em uma população mundial de 2,5 bilhões (NOVAES, 1997).

Há 50 anos atrás, o país era ciclicamente assolado por epidemias devastadoras e uma desnutrição crônica, falta d'água, verminose e diarréias fatais. O personagem de Monteiro Lobato,
Jeca Tatu, de pés descalços, rosto triste e desanimado, representava bem o perfil de saúde do brasileiro deste período. Hoje, de maneira geral, as doenças infecto-contagiosas como poliomielite, coqueluche e difteria, que matavam principalmente crianças, estão cedendo lugar às doenças crônico-degenerativas, como diabetes, hipertensão e câncer, típicas de populações mais idosas (TUNES, 1997).

Embora muitas pessoas pensem que o Brasil é um "país de jovens”, os idosos com 60 anos ou mais perfazem 7,3\% da população. A Organização Mundial de Saúde (OMS) considera um país envelhecido quando a população idosa ultrapassa 7\% do total; portanto, não podemos mais raciocinar em termos de um país de jovens (O ESTADO DO PARANÁ, 1998).

A velhice no Brasil apresenta-se de modo diferenciado, dependendo da região e de níveis

1 Mcstranda do Curso de Pós-Graduação em Ciências de Alimentos do Departamento de Ciência e Tecnologia de Alimentos do Centro de Ciências Agrárias da UFSC e professora do Centro Federal de Educação Tecnológica do Paraná Unidade de Medianeira. Avenida Brasil, 4232, Parque independência, Medianeira - Paraná - CEP: 85884-000. Rua Amaro Antonio Vieira, 2008, apto. ^103, Bloco 08 - Bairro Itacorubi - CEP: 88034-101 - Florianópolis - SC. Fone: (048) 334-2252. E-mail: saraspathy@!globo.com

2 Professora do Curso de Pós-Graduação em Ciências de Alimentos do Departamento de Ciência e Tecnologia dc Alimentos do Centro de Ciências Agrárias da UFSC. Departamento de Ciências dos Alimentos - Centro de Ciências Agrárias Universidade Federal de Santa Catarina. Av. Admar Gonzaga, 1346- Itacorubi - CEP: 88.034-001 - Florianópolis - SC - E-mail: evanilda@cca.ufsc.br 
sócio-econômicos e culturais. Na região sul, com padrão de vida que se aproxima dos países de primeiro inundo, com influência da cultura européia e economia significativa, os idosos têm uma maior longevidade, idêntica à da Itália, Grécia e Espanha, resultando em um tipo de velhice melhor. Já a região Nordeste produz os mais diversos tipos de velhice: dotado deficientemente, velhice precoce e pseudo-velhice (MAGALHÃES, apud BARROSO, 1997). A questão econômica, o ecossistema (secas e enchentes), os padrões culturais, elevados índices de analfabetismo, de doenças endêmicas e economia de sobrevivência, implicam em uma condição semelhante à dos países africanos. O significativo número de octogenários (1 milhão-IBGE/91) representa uma exceção, assim como o número crescente de centenários. Estas expressões de maior longevidade são resultantes de uma junção favorável de fatores genéticos, estilo de vida, auto-cuidados com a saúde, comportamento, ambiência familiar (BARROSO, 1997).

\section{ASPECTOS PSICOSSOCIAIS E AMBIENTAIS}

As pessoas não-idosas percebem a velhice como uma ameaça inevitável, um processo gradual de diminuição das forças e capacidades, um tempo difícil que traz alteração da qualidade de vida, quebra de status social e profissional (NOVAES, 1997).

Se nos reportarmos à década de 1960, e questionarmos sobre quem seria o velho dessa época, encontraríamos duas situações sobre a representação social do idoso. De um lado, os asilados, aqueles que estavam empobrecidos e muitas vezes também doentes, diriam que ser velho era "não ser". Para aqueles que haviam trabalhado em condições reconhecidas pelo poder público e de forma a acumular alguma riqueza, dispensando desta forma o asilo e a caridade, ser velho era ser um vencedor, enquanto para todos os demais velhos, a maioria, a velhice era a época de ser um vencido (SANT'ANNA, 2000).

O substitutivo final do Estatuto do idoso está em votação na Câmara. O deputado Silas Brasileiro (PMDB-MG), relator do projeto de lei 3561/97, avalia que, entre os pontos principais, destacam-se a definição da idade - 60 anos para os benefcies normais e 65 para aqueles que não têm nenhuma fonte de renda -, poder receber benefícios especiais por parte do GOVERNO (FOLHA DE LONDRINA/FOLHA DO PARANÁ,2001). Os anos discriminatórios serão penalizados e, em concursos públicos, não pode- rá ser estabelecido limite de idade. Esta iniciativa vem a clamar pela justiça social para os da melhor idade.

No Brasil o que se verifica é que o atendimento aos idosos pelo Sistema Único de Saúde é deficiente e a sociedade está despreparada, dado o aumento do número de idosos que, se corresponde atualmente a 7,3\% da população atual, em 2025, passará para 15\% (NOVAES, 1997).

Como afirma o geriatra Mário SAYEG (apud NOVAES, 1997), estamos indo rumo a um old boom, ao contrário do baby boom do após guerra, sendo que os próximos passos deverão ser repensados para que, não somente a expectativa do idoso em relação à longevidade seja atingida, mas a sua esperança de uma melhor qualidade de vida, agregando não somente "anos à vida”, mas "vida aos anos".

É crescente o reconhecimento de que o ambiente físico pode intensificar ou impedir a independência e mobilidade dos idosos, havendo sugestões para que sejam direcionados estudos não somente visando a saúde pública, mas também o ambiente físico, para que se aumente a independência e a mobilidade de uma população que está envelhecendo (SATARIANO, 1997).

\section{ASPECTOS FISIOLÓGICOS}

As alterações na fisiologia do organismo aparecem já na terceira década, fenômeno este que os americanos denominam de ho-meoestenose. As pessoas, com o envelhecimento, atravessam muitas mudanças fisiológicas que, adversamente, afetam o consumo de alimentos e a nutrição, de modo que é enfatizado que seja observada a nutrição. Os idosos devem ser criteriosos quanto ao alimento ingerido à medida que a sua sensibilidade para o gosto e o odor decresce ao longo do envelhecimento, o que vem a sugerir, por exemplo, que não notem o leite azedo impróprio para consumo. Para agravar a situação, o sistema imune é também comprometido, permitindo a ocorrência de infecções. Muitos outros fatores também contribuem para a desnutrição, como o metabolismo inadequado dos nutrientes. Por exemplo, para processar o cálcio o organismo necessita de vitamina D, que é fornecido pela luz solar. Contudo, muitos idosos têm pequena exposição ao sol e, quando isto é possivel, sua pele não mais absorve vitamina D como outrora (CONGRESS NEWS, 2001).

A osteoporose é causada pela diminuição de cálcio nos ossos. Com uma quantidade insuficiente desse mineral, o esqueleto fica menos denso, ou seja, mais poroso e, por isso, mais frágil; em consequência, o risco de fraturas nos ossos aumen- 
ta. Os locais do corpo mais afetados são os braços, pulsos, pernas e vértebras. Além disso, há uma diminuição da massa óssea corporal, o que significa que o doente poderá até mesmo diminuir de tamanho. Em casos extremos, dois anos são suficientes para perder 15 centímetros (CONSUMIDOR S. A., 1997).

A mastigação pode tornar-se dolorosa e desagradável. Existe uma tendência a se ingerir alimentos mais moles que, em geral, têm mais calorias em relação ao valor nutritivo das frutas e verduras que são trocadas por eles. Estes alimentos, entretanto, têm menos vitamina A, vitamina C, ácido fálico e fibras, e a mudança do padrão nutricional pode levar a uma ingestão nutricional deficiente e à constipação intestinal. A secreção gástrica diminuida de ácido cloridrico, pepsina, e fator intrínseco, resulta numa digestão imprópria das proteínas, absorção menos eficiente de vitamina $B_{12}$ e uma possibilidade maior de contaminação por bactérias do suco gástrico. A quantidade aumentada de resíduo que resulta da má digestão e absorção pode causar um aumento da flatulência. O movimento gastrintestinal diminuido torna a obstipação um problema freqüente no idoso (KRAUSE, 1985).

A prevenção do estado nutricional dos idosos é um tópico premente para os médicos. De fato, a desnutrição nos idosos está relacionada ao desempenho cognitivo e afetivo prejudicados. A depressão e a demência podem, em algumas situações, ser iniciadas com a perda de peso, e a desnutrição seletiva e subclínica (ácido fálico, vitamina $\mathrm{B}_{12}$ ) pode prejudicar a cognição e a atividade. Os metodos para detecção de deficiências de cianocobalamina e ácido fálico precisam ser revizados, uma vez que as recomendações e niveis séricos destes nutrientes não têm sido ainda estabelecidos para os idosos. A concentração plasmática de ho-mocisteína parece ser um indicador eficiente da inadequada ingestão e biodisponibilidade destas duas vitaminas que, por sua vez, estão relacionadas ao desempenho da cognição e da afetividade nos idosos (SALVIOLI e col., 1998).

A aquisição de alimentos, a leitura de rótulos, bem como a preparação dos alimentos, são dificultadas pela diminuição da acuidade visual. A diminuição da olfação afeta a detecção de alimentos estragados. Estas perdas sensoriais levam a uma negligência com o alimento e quanto aos hábitos alimentares e, com freqüência, há uma perda do apetite (KRAUSE, 1985).

\section{ASPECTOS DE MARKETING}

Atualmente, o mercado mundial de consumo preocupa-se com a redução de gordura total e colesterol, devido aos problemas emergentes da obesidade.

Ainda que o segmento mais rentável seja aquele composto por pessoas de 30 a 39 anos, a terceira idade, como é chamado o grupo que compreende pessoas com mais de 50 anos, tem se tornado um público consumidor a não ser desprezado, pois as projeções indicam que no ano 2050 o Brasil terá a sexta maior população idosa do mundo. Segundo uma pesquisa realizada em Porto Alegre pelo SENAC- RBS (projeto Com a Palavra o Consumidor), a população idosa participa com $19 \%$ da renda brasileira. Entre as atividades mais praticadas, encontram-se assistir a programas de televisão e vídeo, passear, cuidar da casa, visitar e receber amigos e reunir a família nos fins de semana (KARSAKLIAN, 2000).

Segundo PENNA (1999), o número de novos produtos alimentiícios introduzidos no mercado norte-americano alcançou o número de 10.319 em 1993 , sendo que $10 \%$ destes com baixo teor de gordura. O desenvolvimento de novos produtos está em estreita relação com as necessidades e tendências ou modismos de consumo da massa consumidora, o que traz, como conseqüência, que as indústrias de alimentos devem responder com rapidez às mudanças que se detectam no mercado consumidor.

\section{APONTAMENTOS FINAIS}

Entender as necessidades próprias do idoso, descobrindo e aprendendo a atender às suas expectativas, vistas também sob o ponto de vista de consumo e marketing, seria uma forma de reconhecimento da sua identidade como consumidor, não sendo este atendimento apenas privilégio das criancas, adolescentes e adultos jovens. A indústria precisa direcionar suas ações de forma a atender este mercado em ascensão, viabilizando produtos adequados à fisiopatologia do idoso, oferecendo opções que traduzam a praticidade de preparo, valor nutricional e aspectos higiênico-sanitários controlados, sendo que a observância destes fatores vêm ao encontro das necessidades e limitações deste importante segmento populacional. 


\begin{abstract}
The present work analyses some psychosocial and physiological aspects of the elderly, indicating that this population must be seen as a specific consumer market although there has been a signif cant population increase of this age group in Brazil and in the world, the elderly are still discriminated as a consumer market. The paper shows that the food products available in the market must be adequate to the nutritional specificity of the elderly, explaining some characteristics of their nutritional and physiological status to which it should correspond and support.
\end{abstract}

Key words: elderly; physiology; nutritional status; osteoporosis; ageing.

\section{REFERÊNCIAS BIBLIOGRÁFICAS}

BARROSO, J. M. A assistência social e o idoso: um desafio, uma reflexão. Cadernos $A B O N G$, Florianópolis, 19, out. 1997. Disponível em: $<$ http:// www.rebidia.org.br/assis/enas l.html. Acesso em: 10 maio, 2001.

CONGRESS NEWS. Nutrition of the elderly. 3ed. Congress News, Vienna, 29 ago. 2001, p. 2.

CONSUMIDOR. Mantenha o esqueleto em forma. Revista Consumidor S. A., 24: 18- 19, 1907.

FOLHA DE LONDRINA/FOLHADO PARA-NÁ. Deputados encerram Estatuto do idoso. Folha de Londrina /Folha do Paraná, Curiti-ba, 3 set. 2001, p. 5 (Folha da Justiça).

KRAUSE, V. M. Nutrição e dietoterapia. São Paulo: Ed. Roca, 1985. p. 375-392.

KARSAKLIAN, E. Comportamento do consumidor. São Paulo: Ed. Atlas S.A., 2000. p. 1585.

NOVAES, M. H. Psicologia da terceira idade. conquistas possíveis e rupturas necessárias. Rio de Janeiro: Ed. Nau, 1997.

O ESTADO DO PARANÁ. Segredos da longevidade. O Estado do Paraná, Curitiba, 27 jul. 1998. p. 1. (Caderno de Domingo).
PENNA, E. W. Situación del análisis sensorial en los paises iberoamericanos. In: CYTED-Programa Iberoamericano de Ciencia y Tecnologia para el Desarrollo. Avances en análisis sensorial. São Paulo: Ed. Varela, 1999. p. 13-22.

SALVIOLI, G.; VENTURA, J. M.; PRADELLI, M. J. Impact of nutrition on cognition and affectivity in the elderly: a review. Arch. Gerontol. Geriatr., 26 (1001): 459-468, 1998.

SANT'ANNA, R. M. O velho no espelho: um cidadão que envelheceu. Florianópolis: Editora da UFSC, 2000. p. 33-72.

SATARIANO, A.W. The disabilities of aginglooking to the physical environment. Am. J Puhlic Health., 87(3): 331-332, 1997.

TUNES, S.; OLIVEIRA, W. Muda o mapa de nossas doenças. A população envelhece e as doenças infecciosas dão lugar às crônicas. Revista Globo Ciência, 37: 35-39, 1997.

Recebido em 21/06/2002 Modificado em 16/08/2002 Aprovado em 20/08/2002 